OLDER PEOPLE

\title{
Life satisfaction among older people $(65+)$ with reduced self-care capacity: the relationship to social, health and financial aspects
}

\author{
Christel Borg RN, MSc \\ PhD Student, Department of Nursing, Faculty of Medicine, Lund University, Lund, and The School of Health Science, Blekinge \\ Institute of Technology, Karlskrona, Sweden
}

Ingalill R Hallberg RNT, PhD

Professor, Department of Health Sciences, Faculty of Medicine, Lund University, Lund, and The Vardal Institute, The Swedish

Institute for Health Sciences, Sweden

Kerstin Blomqvist RNT, PhD

Senior Lecturer, Department of Health Sciences, Kristianstad University, Kristianstad, Sweden

Submitted for publication: 1 June 2005

Accepted for publication: 22 June 2005

Correspondence:

Christel Borg

Blekinge Institute of Technology

SE-371 79 Karlskrona

Sweden

Telephone: +46455385421

E-mail: christel.borg@bth.se
BORG C, HALLBERG IR \& BLOMQVIST K (2006) Journal of Clinical Nursing 15, 607-618

Life satisfaction among older people $(65+)$ with reduced self-care capacity: the relationship to social, health and financial aspects

Aims and objectives. This study aimed at investigating life satisfaction and its relation to living conditions, overall health, self-care capacity, feeling lonely, physical activities and financial resources among people $(65+)$ with reduced selfcare capacity.

Background. Knowledge about factors related to low life satisfaction among older people with reduced self-care capacity is sparse, although this is important in health care and nursing so that the care is adapted to their needs and perspective. Previous research has mainly focused on isolated aspects such as pain in relation to life satisfaction among older people in general and less among so those with reduced self-care capacity in general.

Design and method. A subsample of 522 persons was selected from a randomly selected cross-sectional survey using a modified form of the Older Americans' Resources Schedule and Life Satisfaction Index Z.

Results. The mean age in the total sample was 77.9; women (79.5) were significantly older than men (77.0). Low life satisfaction was found among women, as well as those living in special accommodations. Life Satisfaction Index Z was $15 \cdot 3$ (SD 5.6) in the total sample. Gender and living conditions did not explain life satisfaction whilst poor overall self-reported health and poor financial resources in relation to needs had the strongest explanatory value. Also of significant importance were loneliness, the degree of reduced self-care capacity and feeling worried.

Conclusion. Life satisfaction in older people with reduced self-care capacity is determined by several factors, with social, physical, mental and financial aspects probably interacting with each other; especially feeling lonely, degree of self-care capacity, poor overall health, feeling worried and poor financial resources in relation to needs. These factors need to be considered in the care of these people to preserve or improve their life satisfaction. 
Relevance to clinical practice. Nursing interventions in terms of preventive home visits, rehabilitation, health education directed towards physical, psychological, social and economic aspects of importance may help to preserve or improve life satisfaction for those with reduced self-care capacity.

Key words: life satisfaction, Life Satisfaction Index Z, nursing care, Older Americans' Resources Schedule, older people, self-care capacity

\section{Introduction}

Older people who are not able to manage daily life by themselves may have a different view of life satisfaction than those with preserved self-care capacity. It may well be that the transition from being healthy and independent of help with activities of daily living to having to live with reduced self-care capacity alters the view of aspects contributing to life satisfaction. Knowledge is sparse about such factors in those with impaired self-care capacity, although this is important in health care and nursing, especially in Sweden, as in many other countries, there is an increasing older population and the average length of life also seems to be increasing (Walker \& Maltby 1997). The proportion of the oldest old ( 80 years of age or above) will increase most in the years to come, which in turn will make demands on the health-care system.

Life satisfaction is a global concept, referring to life as a whole rather than to specific aspects (Bowling 1997). The distinction between life satisfaction and quality of life is not clear and the concepts are sometimes used interchangeably (Mannel \& Dupuis 1996). According to Mannel and Dupuis (1996), p. 60), 'Life satisfaction and morale scales measure more enduring and stable cognitions, whereas happiness scales measure more temporary and transient affective states'. Further, they consider life satisfaction as a well-being measure of quality of life. They also suggest that research on life satisfaction has changed from focusing on pathology and coping to quality of life (Mannel \& Dupuis 1996), which confirms the idea of a strong relation between the concepts. The distinction between healthrelated quality of life and life satisfaction is more obvious since health-related quality of life focuses on factors related to health only (Spiro \& Bossé 2000). Investigating lay definitions of general quality of life among people aged 65 and above, Farquhar (1995) identified several factors of importance for the older people: social contacts, health, activities, family, material circumstances and negatively losing family members - which may be relevant also when investigating life satisfaction among older people with reduced ability to perform daily activities.
Population-based studies including mixed samples of older people have demonstrated that several aspects contribute to life satisfaction. For instance, in a study including 105 older people, aged 90 and above, impaired health showed a low correlation to life satisfaction. However, personality was more strongly related to life satisfaction (Hillerås et al. 2001). In another study of 212 persons, aged 80 years and above, including variables such as social support (contact with children, contact with siblings, contact with friends, number of close friends and satisfaction with friends), satisfaction with friends correlated significantly with life satisfaction and health (need of assistance and self-rated health) and health was found to be strongly related to life satisfaction (McCamish-Svensson et al. 1999). In that study, however, only social network and health were investigated. Other variables with an impact on life satisfaction that have been reported are financial status, which was investigated together with physical functioning, psychological and social support in a sample of 843 men and 714 women, age 70 and above (Ho et al. 1995). In addition, Ho et al. (1995) found physical function and social support to be related to life satisfaction. Although the subjects in the studies described above were not selected on the basis of having reduced capacity to perform activities of daily living, the analysis showed reduced physical function to be related to life satisfaction. Life satisfaction was also investigated in a study of 138 people living in nursing homes $(n=70)$ and $(n=69)$ independently in the community and those living in the community reported higher life satisfaction (Gueldner et al. 2001). McAuley et al. (2000) found in a study of 153 healthy people (mean age 65.5 years) that intervention in the form of physical activities increased life satisfaction and decreased loneliness over the six-month intervention. These improvements, however, had vanished at the 6-month follow-up. Thus, several factors contribute to life satisfaction in older people (Baltes \& Baltes 1990, Farquhar 1995, McCamish-Svensson et al. 1999, McAuley et al. 2000, Hillerås et al. 2001) and the composition of factors as well as their relative weight may change when the older people's life conditions change. It is well known, for instance, that reduced capacity to perform activities of daily living and restricted ability to be alone in older people 
coincides with lower quality of life (QoL) (Hellstrom \& Hallberg 2001). Nyström and Segesten (1990) found from an interview study ( $n=16,68-96$ years old) among older people living in nursing homes that an acceptably comfortable life that allowed the highest independent function possible and a milieu with people to talk with was important. Thus, social aspects as well as independence were important for their life satisfaction. Health and nursing care mainly deal with older people with reduced self-care capacity and therefore knowledge about factors contributing to these people's life satisfaction is needed. Also knowledge from a more comprehensive perspective may form a basis for preventive and interventive actions.

Variables measuring the ability to perform instrumental activities of daily living (IADL) and personal activities of daily living (PADL) need to be included when investigating older people's life satisfaction. However, the relation between life satisfaction and reduced ability to perform daily activities seems to be complex. For example, Bowling and Grundy (1997) found in a follow-up study of three samples $(n=630$, age $85+; n=464$, age $65-84 ; n=276$, age $65-84)$ that impaired functional ability was associated with poor mental health, and depression was negatively associated with life satisfaction (Ho et al. 1995). There seems to be no linear relationship between these factors. For instance, social support may buffer the negative impact on life satisfaction (Hillerås et al. 2001). In addition, the consequences of physical restrictions may contribute to a more restricted life with less involvement in activities and thereby reinforce the feelings of being lonely. Bondevik and Skogstad (1998) found, in a study of 221 older persons aged 80 and above, that dependency in toileting and transferring was related to emotional and social loneliness. Thus, several factors may covary with life satisfaction in older people with reduced selfcare capacity. Knowledge explaining factors of importance to their life satisfaction is needed for nursing staff and for policy-makers to provide care from the older people's perspective, so that they can live with high life satisfaction in spite of infirmities. Knowledge of factors that can compensate for the negative effects of reduced self-care capacity seems especially important.

\section{Aims}

The aim of this study was to investigate life satisfaction in people $(65+)$ with reduced ability to perform activities of daily living. The aim was further to investigate how living conditions, loneliness, self-care capacity, overall health, participation in physical activities and financial resources relate to life satisfaction.

\section{Sample}

For the present study, a subsample from the Swedish part of the European Study of Ageing Well (ESAW) study $n=2803$ project (Ferring et al. 2004) was drawn consisting of 522 persons $65-89$ years old, scoring mildly impaired selfcare capacity or more in activities of daily living (ADL; Fillenbaum 1988). In all, 589 subjects fulfilled the inclusion criteria of reduced self-care capacity. Sixty-seven subjects were excluded as they had not fully completed the Life Satisfaction Index Z (LSIZ) instrument (Wood et al. 1969). An analysis (Chi-squared test and Mann-Whitney U-test) showed no significant difference regarding sex, age and level of education between those included and those who had not fully completed the LSIZ.

The subjects of the Swedish part of the ESAW study came from two southern counties selected to represent Sweden as a whole in the population of people 50-89 years old and distributed in four age groups, 50-59, 60-69, 70-79 and 80-89. Initially, 7034 questionnaires were sent out and 200 were returned with address unknown, leaving 6834 eligible persons. In all, 2803 questionnaires were sent back in useful form; $0 \cdot 2 \%$ were excluded because of high internal dropout, $8.1 \%$ refused on account of health, $22.1 \%$ did not want to participate and $30 \cdot 1 \%$ gave no reason for not participating, which gave an overall response rate in the main study of $41 \cdot 4 \%$. An analysis of dropouts showed that participants were significantly younger than non-participants $(76.0$ years vs. 77.6 years, $P<0.0001)$ and more often men $(54.3 \%$ vs. $46.0 \% P<0.0001)$. The response rate for the age groups from which this subsample was drawn were for male/female, 65-74 (46.9/45.1\%), 75-84 (46.2/37.8\%) and $85+(37 \cdot 2 /$ $26.0 \%)$. The age of 65 and above for the present study was chosen as it is well known that health problems increase with age (Persson et al. 2001, Molarius \& Janson 2002) and the age of 65 is a common starting point for gerontological research (Kerse et al. 1999, Pickering et al. 2001, Huang \& Lin 2002).

\section{Instruments}

The measures used in this analysis were based on a modified version of the Older Americans' Resources and Services schedule (OARS) Multidimensional Functional Assessment Questionnaire (OMFAQ) part A (Fillenbaum 1988), supplemented with a standardized instrument for measuring LSIZ (Wood et al. 1969). The OARS is a multidimensional functional assessment instrument including demographics, physical and mental health, activities of daily living (IADL and PADL), social and economic resources. The question- 
naire was translated into Swedish by a native Swedishspeaking person and thereafter back-translated by a bilingual person (American English) who had not read the original version. Questions about ethnicity, education system, income and health-care system were adapted to the Swedish context. A pilot study was carried out to test the questionnaire.

Ability to perform activities of daily living was assessed using OARS-IADL and OARS-PADL, seven items each (see Table 2), with response alternatives (zero, unable to do; one, with help and two, without help). A new ordinal variable, from the original OARS scoring algorithm as described (George \& Fillenbaum 1985, McCusker et al. 1999), was constructed to obtain a level of self-care capacity, with five categories: no, mild, moderate, severe and total impairment. Test-retest for OARS-IADL at five weeks has been reported to be $r=0.71$ (Fillenbaum 1985). Cronbach's alpha in the present study was 0.83 for IADL and 0.85 for PADL (Cronbach 1951).

Demographic variables (age, marital status, education and assets and financial resources to meet emergencies) included in the analyses were measured with single items from the OARS multidimensional functional questionnaire (Table 1) supplemented with an item to measure living conditions, ordinary housing or special accommodation. Ordinary housing means living at home and special accommodations is a heading for various types of special accommodation (old people's home, nursing home and group dwellings) in Sweden (Swedish Institute 1999). The independent variables (loneli- ness, overall health, feeling worried, physical activities and financial resources) were measured with single items (see Table 3).

Life satisfaction was measured using LSIZ (Wood et al. 1969), which is a shortened version of the Life Satisfaction Index A (Neugarten et al. 1961) including 13 items. The total score ranges from 0 to 26 , with a higher score indicating higher overall life satisfaction (Wood et al. 1969). The LSIZ measures overall life satisfaction, with items such as 'As I grow older, things seem better than I thought they would be', 'This is the dreariest time of my life', 'I am just as happy as when I was younger', 'These are the best years of my life'. Cronbach's alpha was 0.80 in the present study. Based on a sample including $n=1042$ people in the UK (men 406, women 636, 507 aged 65-74 and 535 aged 75 years and above, with those in institutional care excluded) a mean value of $17 \cdot 1$ (SD $5 \cdot 6$; 65-74) and 16.4 (SD 5.5; 75+) was reported (Morgan et al. 1987). The Cronbach's alpha in that sample was 0.74. The instrument has been used previously in Sweden by Hillerås et al. (2001) in a sample of $90+$ years of age with a mean value of $15 \cdot 5$ (SD 4.4) and Cronbach's alpha 0.60.

In addition, the questionnaire included measures assessing self-esteem (Rosenberg 1979), resilience (Wagnhild \& Young 1990), spheres of control (Paulhus \& van Selst 1990), negative and positive affect (Watson et al. 1988) and the Cantril ladder scale (Cantril 1965), although not reported here.

\begin{tabular}{|c|c|c|c|c|}
\hline & $\begin{array}{l}\text { Total } \\
n=522(\%)\end{array}$ & $\begin{array}{l}\text { Male } \\
n=322(\%)\end{array}$ & $\begin{array}{l}\text { Female } \\
n=200(\%)\end{array}$ & $P$-value ${ }^{*}$ \\
\hline \multicolumn{5}{|l|}{ Age } \\
\hline $65-74$ & $31 \cdot 4$ & $34 \cdot 7$ & $26 \cdot 1$ & \multirow[t]{3}{*}{$<0.001$} \\
\hline $75-84$ & $47 \cdot 7$ & $51 \cdot 6$ & $41 \cdot 4$ & \\
\hline $85-89$ & $20 \cdot 9$ & $13 \cdot 7$ & $32 \cdot 5$ & \\
\hline \multicolumn{5}{|l|}{ Marital status } \\
\hline Single/divorced/separated & $9 \cdot 6$ & $7 \cdot 2$ & $13 \cdot 5$ & \multirow[t]{3}{*}{$<0.001$} \\
\hline Married & $66 \cdot 0$ & $81 \cdot 3$ & $41 \cdot 5$ & \\
\hline Widow/widower & $24 \cdot 4$ & $11 \cdot 5$ & $45 \cdot 0$ & \\
\hline \multicolumn{5}{|l|}{ Education } \\
\hline$\leq$ Compulsory school level & $52 \cdot 5$ & $46 \cdot 3$ & $62 \cdot 6$ & \multirow{3}{*}{$<0.001$} \\
\hline Upper secondary education & $29 \cdot 5$ & $31 \cdot 6$ & $25 \cdot 8$ & \\
\hline University studies & $18 \cdot 0$ & $22 \cdot 1$ & $11 \cdot 6$ & \\
\hline \multicolumn{5}{|l|}{$\begin{array}{l}\text { Assets and financial resources } \\
\text { sufficient to meet emergencies }\end{array}$} \\
\hline Yes & $85 \cdot 0$ & $90 \cdot 9$ & $75 \cdot 5$ & \multirow[t]{2}{*}{$<0.001$} \\
\hline No & $15 \cdot 0$ & $9 \cdot 1$ & $24 \cdot 5$ & \\
\hline \multicolumn{5}{|l|}{ Living condition } \\
\hline Ordinary housing & $92 \cdot 9$ & $96 \cdot 3$ & $87 \cdot 5$ & \multirow[t]{2}{*}{$<0.001$} \\
\hline Special accommodations & $7 \cdot 1$ & $3 \cdot 7$ & $12 \cdot 5$ & \\
\hline
\end{tabular}

Table 1 Description of demographic variables and gender differences

*Chi-squared test was used to test significant difference between variables. 
Table 2 Description of self-care capacity in activities of daily living and differences by gender

\begin{tabular}{|c|c|c|c|c|c|}
\hline & \multicolumn{2}{|c|}{ Male $(n=322)$} & \multicolumn{2}{|c|}{ Female $(n=200)$} & \multirow[b]{2}{*}{$P$-value } \\
\hline & $\begin{array}{l}\text { With help } \\
(\%)\end{array}$ & $\begin{array}{l}\text { Unable to do } \\
(\%)\end{array}$ & $\begin{array}{l}\text { With help } \\
(\%)\end{array}$ & $\begin{array}{l}\text { Unable to do } \\
(\%)\end{array}$ & \\
\hline \multicolumn{6}{|l|}{ IADL } \\
\hline Can use a telephone & $3 \cdot 4$ & $2 \cdot 5$ & $5 \cdot 5$ & $4 \cdot 5$ & $0 \cdot 219$ \\
\hline Can get to places that are not within walking distance & $15 \cdot 2$ & $0 \cdot 9$ & $40 \cdot 0$ & $8 \cdot 5$ & $<0 \cdot 001$ \\
\hline Can go shopping & $18 \cdot 9$ & $5 \cdot 9$ & $39 \cdot 5$ & $13 \cdot 0$ & $<0 \cdot 001$ \\
\hline Can prepare meals & $58 \cdot 7$ & $16 \cdot 8$ & $18 \cdot 0$ & $8 \cdot 5$ & $<0 \cdot 001$ \\
\hline Can do housework & $44 \cdot 0$ & $11 \cdot 5$ & $59 \cdot 5$ & $15 \cdot 5$ & $<0.001$ \\
\hline $\begin{array}{l}\text { When needing to take medication are you able to remember } \\
\text { to take your own medicine? }\end{array}$ & $10 \cdot 2$ & $1 \cdot 6$ & $10 \cdot 5$ & $9 \cdot 0$ & $<0.001$ \\
\hline Can handle own economy & $13 \cdot 0$ & $5 \cdot 3$ & $32 \cdot 0$ & $10 \cdot 0$ & $<0.001$ \\
\hline \multicolumn{6}{|l|}{ PADL } \\
\hline Can eat & $4 \cdot 3$ & $0 \cdot 0$ & $7 \cdot 5$ & $2 \cdot 0$ & $<0.001$ \\
\hline Can dress and undress & $4 \cdot 7$ & $1 \cdot 9$ & $7 \cdot 5$ & $4 \cdot 0$ & $0 \cdot 124$ \\
\hline Can take care of own appearance & $2 \cdot 8$ & $1 \cdot 2$ & $7 \cdot 5$ & $3 \cdot 5$ & $0 \cdot 008$ \\
\hline Can walk by yourself & $15 \cdot 2$ & $0 \cdot 9$ & $40 \cdot 0$ & $8 \cdot 5$ & $<0.001$ \\
\hline Can get in and out of bed & $2 \cdot 5$ & $1 \cdot 2$ & $7 \cdot 5$ & $4 \cdot 0$ & $<0.001$ \\
\hline Can take a bath or shower & $6 \cdot 2$ & $2 \cdot 5$ & $18 \cdot 0$ & $8 \cdot 5$ & $<0.001$ \\
\hline Do you ever have trouble getting to the toilet on time? & $5 \cdot 6$ & $4 \cdot 3 \dagger$ & $11 \cdot 5$ & $13 \cdot 5 \dagger$ & $<0.001$ \\
\hline
\end{tabular}

*Comparison between genders using Chi-squared test.

$\dagger$ Use of catheter included. The third response alternative was without help.

\section{Data collection and ethical considerations}

Data were collected during spring 2001 and autumn 2002. The questionnaire was sent by mail together with a letter of introduction and an assurance that participation was voluntary. If needed, subjects were offered help to answer the questionnaire in their own home. Questionnaires with high internal dropout were completed through a telephone interview. The Ethics Committee of the Medical Faculty of Lund University approved the study (LU 545-99).

\section{Data analysis}

Differences between men and women in nominal data were tested by Chi-squared test. Differences in mean LSIZ with regard to age, gender, living conditions, loneliness, self-care capacity, overall health, feeling worried, participation in physical activities and financial resources in relation to needs were tested by non-parametric one-way analysis of variance the Kruskal-Wallis test and the Mann-Whitney $U$-test (Altman 1991). A $P$-value of 0.05 was regarded as significant and a reduced $P$-value of 0.017 in the post hoc test. Spearman rank correlation was used to test the correlation between the independent and dependent variable (Altman 1991). A multivariate logistic regression analysis (forward stepwise likelihood ratio), controlling for age and gender was performed to determine factors significantly associated with low life satisfaction (Hosmer \& Lemeshow 2000). Logistic regression was chosen as all the independent variables were on nominal or ordinal level (Altman 1991). The dependent variable (LSIZ; ordinal scale $0-26$ ) was transformed into a categorical variable using the 25th percentile (value 11) as the cutoff point for low life satisfaction. Variables that in the bivariate analyses (Spearman rank correlation) were associated with low life satisfaction $(P<0 \cdot 10$; living conditions $0 \cdot 23$, self-care capacity $0 \cdot 38$, loneliness $0 \cdot 44$, physical health 0.45 , feeling worried 0.40 , physical activities 0.27 and financial resources 0.29) were entered into the model. For each item the response alternative anticipated as most favourable to high life satisfaction was chosen as reference category (for categorical variables; Polit 1996), i.e. ordinary housing for living conditions, mild impairment for self-care capacity, excellent for physical health, hardly ever for feeling worried, almost never for loneliness, yes for participation in physical activities, very well for financial resources (Polit 1996). For age and gender the youngest age group and male sex were used as reference category. Statistical analyses were carried out using SPSS 11.5 for Windows (Puri 2002).

\section{Results}

The mean age of the sample in this study was 77.9 (SD 6.4). Sixty-six percent were married and 93\% lived in their ordinary housing. Sixty-seven percent were living together 
Table 3 Demographics and other variables in relation to life satisfaction (LSIZ)

\begin{tabular}{|c|c|c|c|c|}
\hline$n=522$ & $\%$ & LSIZ m (SD) & LSIZ md (q1-q3) & $P$-value* \\
\hline \multicolumn{5}{|l|}{ Age } \\
\hline $65-74$ & $31 \cdot 4$ & $16 \cdot 2(6 \cdot 1)$ & $17 \cdot 0(11-21)$ & \multirow[t]{3}{*}{0.034} \\
\hline $75-84$ & $47 \cdot 7$ & $15 \cdot 5(5 \cdot 3)$ & $16 \cdot 0(12-20)$ & \\
\hline $85-89$ & $20 \cdot 9$ & $13 \cdot 4(5 \cdot 4)$ & $13 \cdot 0(9-18)$ & \\
\hline \multicolumn{5}{|l|}{ Gender } \\
\hline Male & $61 \cdot 7$ & $16 \cdot 3(5 \cdot 5)$ & $16 \cdot 0(12-20)$ & \multirow[t]{2}{*}{$<0.001$} \\
\hline Female & $38 \cdot 3$ & $13 \cdot 8(5 \cdot 4)$ & $14 \cdot 0(10-18)$ & \\
\hline \multicolumn{5}{|l|}{ How do you live right now? } \\
\hline Ordinary housing & $92 \cdot 9$ & $15 \cdot 6(5 \cdot 5)$ & $16 \cdot 0(12-20)$ & \multirow[t]{2}{*}{$<0.001$} \\
\hline Special accommodation & $7 \cdot 1$ & $10 \cdot 8(5 \cdot 3)$ & $10 \cdot 0(8-13)$ & \\
\hline \multicolumn{5}{|c|}{ Do you find yourself feeling lonely? } \\
\hline Almost never & $59 \cdot 0$ & $17 \cdot 2(5 \cdot 0)$ & $18 \cdot 0(14-21)$ & \multirow[t]{3}{*}{$<0.001$} \\
\hline Sometimes & $27 \cdot 5$ & $13 \cdot 7(5 \cdot 3)$ & $13 \cdot 0(10-17)$ & \\
\hline Quite often & $13 \cdot 5$ & $10 \cdot 2(4 \cdot 8)$ & $10 \cdot 0(7-13)$ & \\
\hline \multicolumn{5}{|l|}{ Self-care capacity } \\
\hline Mild impairment & $35 \cdot 9$ & $15 \cdot 3(5 \cdot 1)$ & $15 \cdot 0(12-19)$ & \multirow[t]{4}{*}{$<0.001$} \\
\hline Moderate impairment & $49 \cdot 4$ & $16 \cdot 5(5 \cdot 6)$ & $17 \cdot 0(12-20)$ & \\
\hline Severe impairment & $6 \cdot 5$ & $11 \cdot 1(5 \cdot 2)$ & $10 \cdot 5(8-15)$ & \\
\hline Total impairment & $8 \cdot 2$ & $10 \cdot 9(4 \cdot 7)$ & $10 \cdot 0(8-14)$ & \\
\hline \multicolumn{5}{|c|}{ How would you rate your overall health at the present time? } \\
\hline Excellent & $7 \cdot 1$ & $20 \cdot 4(4 \cdot 5)$ & $21 \cdot 0(16-26)$ & \multirow[t]{4}{*}{$<0.001$} \\
\hline Good & $31 \cdot 5$ & $17 \cdot 5(4 \cdot 9)$ & $18 \cdot 0(14 \cdot 25-21)$ & \\
\hline Fair & $48 \cdot 1$ & $14 \cdot 4(5 \cdot 2)$ & $15 \cdot 0(10-18 \cdot 75)$ & \\
\hline Poor & $13 \cdot 3$ & $10 \cdot 3(4 \cdot 7)$ & $10 \cdot 0(6 \cdot 5-14)$ & \\
\hline \multicolumn{5}{|c|}{ How often would you say that you worry about things? } \\
\hline Hardly ever & $39 \cdot 2$ & $17 \cdot 8(5 \cdot 1)$ & $19 \cdot 0(15-21)$ & \multirow[t]{3}{*}{$<0 \cdot 001$} \\
\hline Fairly often & $44 \cdot 7$ & $14 \cdot 6(5 \cdot 1)$ & $15 \cdot 0(10-19)$ & \\
\hline Very often & $16 \cdot 1$ & $11 \cdot 2(5 \cdot 3)$ & $11 \cdot 0(7-15)$ & \\
\hline \multicolumn{5}{|c|}{ Do you regularly (at least once a week) participate in physical activities - such as walking, gardening, swimming etc? } \\
\hline Yes & $67 \cdot 2$ & $16 \cdot 3(5 \cdot 4)$ & $17 \cdot 0(13-20)$ & \multirow[t]{2}{*}{$<0.001$} \\
\hline No & $32 \cdot 8$ & $13 \cdot 2(5 \cdot 5)$ & $13 \cdot 0(9-17)$ & \\
\hline \multicolumn{5}{|c|}{ How well do you feel your needs are met by financial resources? } \\
\hline Very well & $26 \cdot 4$ & $17 \cdot 3(5 \cdot 6)$ & $18 \cdot 0(14-22)$ & \multirow[t]{3}{*}{$<0.001$} \\
\hline Fairly well & $64 \cdot 3$ & $15 \cdot 2(5 \cdot 3)$ & $15 \cdot 0(12-19)$ & \\
\hline Poor & $9 \cdot 3$ & $10 \cdot 4(5 \cdot 2)$ & $10 \cdot 0(6-14)$ & \\
\hline
\end{tabular}

Internal dropout $0-7$.

"Non-parametric one-way of analysis of variance - the Kruskal-Wallis test and the Mann-Whitney U-test were used to test significant differences between the response alternatives. In order to permit comparison with other studies both mean (SD) and median (q1-q3) are presented.

with someone. Women were significantly older, more often widowed, had lower education, worse financial resources, and lived to a higher extent in special accommodations than men $(P<0.0001$; Table 1$)$.

\section{Activities of daily living}

Some $14.7 \%$ of the subjects were severely or totally impaired in activities of daily living. The impairments in the self-care capacity among men were mainly concentrated in housework $(55.5 \%)$ and preparing meals $(75.5 \%)$, whereas impairments among women concerned doing housework (75\%), going shopping $(52.5 \%)$, getting to places outside walking distance $(48 \cdot 5 \%)$, and handling money $(42 \cdot 0 \%)$. Impairments in PADL were commonly mobility problems and especially among women, i.e. walking by themselves (48.5\%), taking a bath $(26.5 \%)$ and trouble getting to the toilet on time $(25 \cdot 0 \%)$ were more common than among men $(16 \cdot 1,8 \cdot 2$ and $9.9 \%$; Table 2).

\section{Life satisfaction}

Life Satisfaction Index Z in the total sample was $15 \cdot 3$ (SD 5.6). Higher life satisfaction was found among those with 
Table 4 Logistic regression analysis of factors predicting low life satisfaction

\begin{tabular}{lcr}
\hline & OR $(95 \%$ CI for OR) & $P$-value \\
\hline Loneliness sometimes & $2 \cdot 6(1 \cdot 5-4 \cdot 6)$ & $<0 \cdot 001$ \\
Loneliness quite often & $3 \cdot 4(1 \cdot 6-7 \cdot 2)$ & $<0 \cdot 001$ \\
Self-care capacity moderate impairment & $1 \cdot 6(0 \cdot 9-2 \cdot 9)$ & $0 \cdot 133$ \\
Self-care capacity severe impairment & $3 \cdot 3(1 \cdot 3-8 \cdot 9)$ & $0 \cdot 013$ \\
Self-care capacity total impairment & $4 \cdot 3(1 \cdot 8-10 \cdot 3)$ & $<0 \cdot 001$ \\
Overall health good & $3 \cdot 8(0 \cdot 5-30 \cdot 6)$ & $0 \cdot 208$ \\
Overall health fair & $6 \cdot 5(0 \cdot 8-50 \cdot 6)$ & $0 \cdot 074$ \\
Overall health poor & $19 \cdot 6(2 \cdot 2-160 \cdot 6)$ & $0 \cdot 006$ \\
Feeling worried often & $1 \cdot 7(0 \cdot 9-3 \cdot 1)$ & $0 \cdot 078$ \\
Feeling worried very often & $2 \cdot 7(1 \cdot 2-5 \cdot 8)$ & $0 \cdot 012$ \\
Financial resources in relation to needs fairly well & $1 \cdot 4(0 \cdot 8-2 \cdot 6)$ & $0 \cdot 245$ \\
Financial resources in relation to needs poor & $10 \cdot 6(4 \cdot 3-26 \cdot 2)$ & $<0 \cdot 001$ \\
\hline
\end{tabular}

OR, odds ratio; CI, confidence interval.

Hosmer and Lemeshow goodness-of-fit test $P=0.920$. Factors without significant influence were: living conditions, participation in physical activities, self-care capacity moderate impaired, overall health good, worry fairly often, financial resources in relation to needs fairly good, gender and age. lower age, living in ordinary housing, lower feelings of loneliness, higher self-care capacity, better overall self-reported health, higher level of participation in physical activities, lower degree of feeling worried, better economic resources and being male (Table 3).

Factors significantly predicting low life satisfaction were poor overall self-reported health [Odds ratio (OR) 19.6], poor financial resources in relation to needs (OR 10.6), severe (OR 3.3) and totally impaired (OR 4.3) self-care capacity, feeling lonely quite often (OR 3.4) and sometimes (OR 2.6), feeling worried very often (OR 2.7) (Table 4). Poor self-rated health with an OR of 19.6 and poor financial resources in relation to needs with an OR of 10.6 were most strongly related to low life satisfaction, whilst age, gender, living conditions and participation in physical activities did not explain low life satisfaction.

\section{Discussion}

Questions about generalizations need to be considered, and here the low response rate is one limitation. This sample of older people with reduced ability to perform activities of daily living is frail, which may have affected the response rate. The dropouts were significantly older than those included in the study. It is well known that health problems increase with age (Molarius \& Janson 2002). In particular, this concerns cognitive impairments such as dementia (Rowe \& Kahn 1998). This may explain the considerably lower response rate in the higher age groups (Norton et al. 1994). The analysis of dropouts also showed a significant difference in gender, with more men than women participating. Older women have been found to have poorer health than men (Molarius \& Janson 2002), which could be one reason for the higher participation of men in this study. Other possible reasons for the dropout could be the comprehensiveness of the postal questionnaire. There is also an increasing negative trend in society towards participation in this type of studies, especially among the oldest (Kaldenberg et al. 1994). A response rate above $60 \%$ is preferable to avoid response bias, but lower response rates are common (Polit \& Hungler 1999). However, the purpose of this study was not to investigate prevalence, but to explore factors of importance for life satisfaction among older people with reduced self-care capacity. Thus, results may be generalized to older people with reduced self-care capacity, with the reservation for the older people with the greatest infirmities and also reservation about women. Results may give a more positive view of life satisfaction in these people with reduced self-care capacity than is actually the case.

Although comprehensive, measures included in the questionnaire were developed and tested for use in samples of older people (Wood et al. 1969, Fillenbaum 1988); the LSIZ, for instance, has been used in Sweden in about the same time as this study (Hillerås et al. 2001). A common problem in gerontological research is the lack of instruments adjusted for older people. The internal dropout was low, probably because of the use of instruments developed for people 65 and above. Also, the high internal consistency for LSIZ showed the instrument to be reliable in that sense (Streiner $\&$ Norman 1995) and similar to results in the original publication (Wood et al. 1969). Also it seemed sensitive enough to discriminate for various factors. The present study 
was cross-sectional and no further tests, for instance testretest reliability (Polit \& Hungler 1999), were carried out and should be done before further use.

Although the questionnaire was based on self-reports, about one-third of this frail group had received help, mainly from relatives, to fill in the questionnaire. There is a risk that this procedure affected responses. It is probably common for a family member to help when a postal questionnaire is sent to a person in a household, but it is seldom investigated or reported. Knowledge about how many persons received this help could be viewed as a finding outside the aim of the study and as a strength. It cannot, however, be stated whether this has biased the results in any directions in terms of it becoming visible.

Translation of instruments into another language than its original is not without problem (Fukuhara et al. 1998). In this study, forward-backward translation was used, which may be too simple a procedure. The questionnaire was tested in a pilot study and found feasible and minor adjustments were made. For instance, the youngest age group did not like the term 'ageing well', which was therefore the title was changed to 'well-being'. A study of a translation from English to Japanese showed forwardbackward translation to be insufficient and that traditional psychometrics such as coefficient alpha were unable to detect the problems (Fukuhara et al. 1998). Fukuhara suggested that psychometric testing with factor analysis and focus group discussion was needed to guarantee quality in the translation process. Also testing the instrument for differential item functioning (DIF; Petersen et al. 2003) may indicate the possibilities of single items. The results of this study, however, are in agreement with previous studies (Wood et al. 1969, Ho et al. 1995). Further testing may still be needed in the Swedish context.

The findings indicate that several factors were related to low life satisfaction for older people. Thus, life satisfaction among these people with reduced self-care capacity stood out as multidimensional (i.e. depending on, e.g. social, physical, activity-related, mental and economic factors), which needs to be considered in nursing care with the focus on preventive and compensative actions to improve life satisfaction. Krach et al. (1996) likewise showed that the five domains of functioning - social, economic, mental, physical and ADL had significant relationships to life satisfaction. In the present study, a score of LSIZ under the 25th percentile was found, for example, among those reporting feelings of loneliness quite often, poor self-rated health, severe and total impairment in the performance of daily activities, poor financial situation and living in special accommodation. The LSIZ mean score for these variables ranged between $10 \cdot 2$ and $10 \cdot 9$ whilst LSIZ in the total sample was $15 \cdot 3$. In comparison with the mean value $(16 \cdot 4-17 \cdot 1)$ for life satisfaction found by Morgan et al. (1987), lower scores were obtained in this study for those who felt lonely quite often, had poor selfrated health, were severely or totally impaired in activities of daily living, had a poor financial situation and lived in special accommodations. There is reason to believe that there is an interaction between the variables, which means that a low value on one variable adds to low value in other variables as well. If this is the case, it makes the care of older people complex and comprehensive care is needed. It implies that it is not sufficient to establish rehabilitation in one area; instead, the rehabilitation and support need to integrate physical, psychological, social and financial conditions. This group of people with reduced self-care capacity, with an extremely low level of life satisfaction, is therefore particularly important to capture for health-care professionals so that steps can be taken in terms of primary as well as secondary interventions.

Life satisfaction was also significantly lower among women and in higher age. However, women were older, to a higher extent widowed, had lower education, poorer financial resources to meet emergencies and lived in special accommodations to a higher extent than men, which may explain women's lower life satisfaction rather than gender per se. Previous results regarding the importance of age and gender for life satisfaction are divided. Mannel and Dupuis (1996), for instance, described a weak relation between gender, age and life satisfaction. In another study of older people Chen (2001) showed that life satisfaction decreased with age after controlling for demographics and ageing. This change was ascribed to the cohort effect, i.e. the specific living conditions are supposed to have affected the way a certain age group viewed their life. It may well be that gender and age have a subordinate effect on older people's life satisfaction and that it is factors such as loneliness, reduced self-care capacity, poor overall health, feeling worried and poor financial resources that have a significant impact on older people's life satisfaction. Neither gender nor age explained life satisfaction in the regression analysis, supporting the idea that it is not age and gender per se that have an impact but the life conditions that go along with age and gender. It is, for instance, well known that women have a poorer economy and health throughout the life span (Walker 2005), thus it may be that women in this study had a poorer starting position before they became reduced in self-care capacity. Women may need extra attention from health-care professionals and in nursing care, which also was reported by Tannenbaum \& Mayo (2003). Also, it has been found that women benefit more than men from preventive home visits (Vass et al. 2004). 
The degree of self-care capacity stood out as significant for life satisfaction. LSIZ was low (mean 10.9-11.1) and OR varied between 3.3 and 4.3 among those with severely or totally reduced self-care capacity, who accounted for $14.7 \%$ of the sample. Previous research has demonstrated that reduced self-care capacity, which complicates activities of daily living has a stronger negative correlation with life satisfaction than chronic diseases (Mannel \& Dupuis 1996). Thus, it is not having a disease but the effect in terms of reduced self-care capacity brought about by the disease that reduces life satisfaction. The type of reduced self-care capacity differed significantly between genders. Men needed help with preparing meals and household tasks to a higher extent, whereas women needed help with tasks to do with mobility, for instance, getting to places outside walking distance $(48.5 \%$ compared with $16 \cdot 1 \%$ among men) and shopping $(52.5 \%$ compared with $24.8 \%$ among men; Table 4), indicating that women had a poorer self-care capacity. Farquhar (1995) reported that mobility was the most important negative factor for older people's quality of life. Mobility restrictions may prevent them from doing things that they want to do and which are needed to live an independent life. Nearly $50 \%$ of the women in this study could not handle activities that are vital for living an independent life, which suggests that they were worse off than men. Perhaps older people may resign themselves to the fact that ageing means lower self-care capacity and thus refrain from preventive actions. Home-visiting work (Stuck et al. 2002) with the motive to offer preventive as well as rehabilitating actions (Tannenbaum \& Mayo 2003) may be one way to retain a high degree of self-care capacity. Previous work with rehabilitation of older people has shown that home-based prehabilitation programmes are effective in preventing decline in activities of daily living (Gill et al. 2003). Thus, intervention with the intention of preserving a high degree of self-care capacity among older people needs to be prioritized, for older people living in the community and for those living in special accommodations. It may help older people to greater life satisfaction and make work easier for staff in elder care.

The view of health also seems to be fundamental to older people's life satisfaction. Poor self-rated health had the highest OR, 19.3 (CI was widely spread, 2·2-160, indicating low variation) among the associated variables, thus for those with poor self-rated health the odds of having low life satisfaction were nineteen times higher than for those with excellent health. This has been found in other studies as well (Farquhar 1995, Hachisuka et al. 1999, McCamish-Svensson et al. 1999, Hillerås et al. 2001). Mannel and Dupuis (1996) stated that perceived health is the best single predictor of life satisfaction for older people. However, there may well be a redundancy between self-reported health and life satisfaction in that people report an overall evaluation of their life when asked about their health. The Spearman rank correlation between self-reported health and life satisfaction was 0.45 ; there was thus a connection, although moderate, between these variables. Self-reported health consequently seems to be one of the most important variables among older people with reduced self-care capacity.

Poor financial resources explained life satisfaction to a great extent among older people with reduced self-care capacity (OR 10·6, CI 4-3-26.2). Poor economy as a predictor of low life satisfaction has previously been emphasized by Ho et al. (1995) and Bowling and Windsor (2001). Furthermore, Thumboo et al. (2003), investigating factors important for quality of life among people aged 65 and below, found that socio-economic status (SES) was important for physical functioning. Financial problems may lead to restrictions in a person's ability to live an independent life, to fulfil needs or wishes to socialize and to compensate for reduced self-care capacity. Thus, poor financial resources seem to be important for older people's life satisfaction. Assessing economic conditions is not commonly regarded as a task for nursing care. Perhaps that is a mistake, especially when it comes to older women, as their poor economy may also influence their medical treatment. Primary care and the district nurses often have the first contact with those needing care and the staff are often persons that older people have confidence in, whereas social workers may be more unfamiliar. Nurses can thus identify the problem and alert social workers who are more knowledgeable about available help.

In addition to health and poor financial resources, loneliness was important among older people in that $40.0 \%$ reported that they felt lonely sometimes or quite often. This study, like others (Holmen et al. 1992, Bondevik \& Skogstad 1996), has highlighted the problem of loneliness among older people. It is well known that loneliness is associated with lower life satisfaction (Farquhar 1995, Holmen et al. 1999). Thus, an important aspect may be to support the preservation of the social network (informal and/or formal) that may help and support the older people when their self-care capacity is insufficient. Integrating family members in the older people's health care may strengthen their relationship. But also for those older people without a sufficient social network, it is necessary to offer help and support that can reduce their feeling of loneliness. Home-based support (Elkan et al. 2001) may be one way to reach older people feeling lonely. Home-based support or home visits (Stuck et al. 2002) have further been found to have a positive effect in terms of preventing nursing home admission and 
functional decline and in reducing mortality (Elkan et al. 2001, Stuck et al. 2002). Thus, as those with reduced selfcare capacity seem to have low life satisfaction depending on physical, psychological, social as well as economic aspects, preventive home visits including comprehensive assessments and interventions may be helpful to preserve high life satisfaction among them.

\section{Conclusions}

Previous research on this topic has mainly focused on separate aspects such as pain in relation to life satisfaction among older person in general. Knowledge about what brings life satisfaction among older people with impaired self-care capacity is important especially for the older people themselves, staff in the care of older people as well as for policymakers, so that older people's needs can be met and care can be shaped from the older people's needs and perspective. Most important for low life satisfaction among older people with reduced self-care capacity were poor overall health, not having enough money in relation to needs, impaired ability to perform activities of daily living, loneliness and feeling worried. Preventive home visits to older people may be one way to capture those people needing support. This knowledge also gives an opportunity for health-care professionals as well as policy makers to plan for interventions such as meaningful activities, health-care education and rehabilitation with the intention of preserving a high level of functional ability, participation in preventive health care, which in turn may reduce feelings of loneliness and worry. It may also be important to highlight the fact that poor economy had a great impact on older people's life satisfaction, which can ultimately influence their ability to pay for treatment, medicines, and aids such as glasses. The care of older people thus needs an interdisciplinary approach that not only focuses on the medical problem but also nurses working in teams together with other geriatric disciplines to preserve a high level of factors of importance for life satisfaction among older people with reduced self-care capacity.

\section{Acknowledgements}

The ESAW Project was designed as part of the Global Ageing Initiative, initiated by the Indiana University Center on Aging and Aged, under the directorship of Dr Barbara Hawkins. ESAW, funded by the European Union QLRT2001-00280, represents a European subgroup of the larger global study, which aims to develop a European model of Adult Well-being, using the five key components and parallel methodology. The ESAW partner countries are:
Austria, Italy, Luxembourg, the Netherlands, Sweden and UK. The work has been co-ordinated by Professor G. Clare Wenger of the University of Wales, Bangor, UK. The European Union has no responsibility for the results of this study. The authors wish to thank all the subjects for participating in the present study. We would also like to thank Dr Barbara Hawkins, Indiana University, for starting this project, the project group in ESAW, Cecilia Fagerström, Anna Condelius, and John Tällberg for help with data collection and data input and Per Nyberg for help with statistics, Inger Andersson and Vicky Gatzuras for help with back-translation of the questionnaire. Special thanks to Alan Crozier for help with the English language. This work was also supported by grants from the Vårdal Foundation V2000 112, Länsförsäkringar P7/01, the European Commission QLRT-2001-00280, the Department of Nursing, Faculty of Medicine, Lund University, and School of Health Science, Blekinge Institute of Technology.

\section{Contributions}

Study design: $\mathrm{CB}$, IRH; data collection and analysis: $\mathrm{CB}$, IRH, KB; manuscript preparation: $\mathrm{CB}$, IRH, KB.

\section{References}

Altman DG (1991) Practical Statistics for Medical Research. Chapman \& Hall, London.

Baltes PM \& Baltes MM (1990) Psychological perspectives on successful aging: the model of selective optimization with compensation. In Successful Aging Perspectives from the Behavioral Sciences (Baltes PM \& Baltes MM eds). Cambridge University Press, New York, pp. 1-34.

Bondevik M \& Skogstad A (1996) Loneliness among the oldest old, a comparison between residents living in nursing homes and residents living in the community. International Journal of Aging and Human Development 43, 181-197.

Bondevik M \& Skogstad A (1998) The oldest old, ADL, social network, and loneliness. Western Journal of Nursing Research 20, 325-343.

Bowling A (1997) Measuring Health. A Review of Life Measurement Scales. Open University Press, Buckingham.

Bowling A \& Grundy E (1997) Activities of daily living: changes in functional ability in three samples of elderly and very elderly people. Age and Ageing 26, 107-114.

Bowling A \& Windsor J (2001) Towards the good life: a population survey of dimensions of quality of life. Journal of Happiness Studies 2, 55-81.

Cantril H (1965) The Pattern of Human Concerns. Rutgers University Press, New Brunswick.

Chen C (2001) Aging and life satisfaction. Social Indicators Research $54,57-79$.

Cronbach LJ (1951) Coefficient alpha and the internal structure of tests. Psychometrika 16, 297-339. 
Elkan R, Kendrick D, Dewey M, Hewitt M, Robinson J, Blair M, Williams D \& Brummell K (2001) Effectiveness of home based support for older people: systematic review and meta-analysis. BMJ 323, 719-725.

Farquhar M (1995) Elderly people's definitions of quality of life. Social Science and Medicine 41, 1439-1446.

Ferring D, Balcucci C, Burholt V, Thissen F, Weber G \& Hallberg IR (2004) Life satisfaction of older people in six European countries: findings from the European study of adults well-being. European Journal of Ageing 1, 15-25.

Fillenbaum GG (1985) Screening the elderly. A brief instrumental activities of daily living measure. Journal of the American Geriatrics Society 33, 698-706.

Fillenbaum GG (1988) Multidimensional Functional Assessment of Older Adults: The Duke Older Americans Resources and Services Procedures. Lawrence Erlbaum Associates, Durham.

Fukuhara S, Bito S, Green J, Hsiao A \& Kurokawa K (1998) Translation, adaptation, and validation of the SF-36 health survey for use in Japan. Journal of Clinical Epidemiology 51, 1037-1044.

George LK \& Fillenbaum GG (1985) OARS methodology. A decade of experience in geriatric assessment. Journal of the American Geriatrics Society 33, 607-615.

Gill TM, Baker DI, Gottschalk M, Gahbauer E, Charpentier PA, de Regt TP \& Wallace SJ (2003) A prehabilitation program for physically frail community-living older persons. Archives of Physical Medicine and Rehabilitation 84, 394-404.

Gueldner SH, Loeb S, Morris D, Penrod J, Bramlett M, Johnston L \& Schlotzhauer P (2001) A comparison of life satisfaction and mood in nursing home residents and community-dwelling elders. Archives of Psychiatric Nursing 15, 232-240.

Hachisuka K, Tsutsui Y, Kobayashi M \& Iwata N (1999) Factor structure of satisfaction in daily life of elderly residents in Kitakyushu. Journal of UOEH 21, 179-189.

Hellstrom Y \& Hallberg IR (2001) Perspectives of elderly people receiving home help on health, care and quality of life. Health and Social Care in the Community 9, 61-71.

Hillerås P, Jorm A, Herlitz A \& Winblad B (2001) Life satisfaction among the very old: a survey on a cognitively intact sample aged 90 years and above. International Journal Aging and Human Development 52, 71-90.

Ho SC, Woo J, Lau J, Chan SG, Yuen YK, Chan YK \& Chi I (1995) Life satisfaction and associated factors in older Hong Kong Chinese. Journal of the American Geriatrics Society 43, 252-255.

Holmen K, Ericsson K, Andersson L \& Winblad B (1992) Loneliness among elderly people living in Stockholm: a population study. Journal of Advanced Nursing 17, 43-51.

Holmen K, Ericsson K \& Winblad B (1999) Quality of life among the elderly. State of mood and loneliness in two selected groups. Scandinavian Journal of Caring Sciences 13, 91-95.

Hosmer DW \& Lemeshow S (2000) Applied Logistic Regression. Wiley-Interscience, New York.

Huang LH \& Lin YC (2002) The health status and needs of community elderly living alone. Journal of Nursing Research 10, 227-236.

Kaldenberg DO, Koenig HF \& Becker BW (1994) Mail survey response rate patterns in a population of the elderly. Public Opinion Quarterly 58, 68-76.

Kerse NM, Flicker L, Jolley D, Arroll B \& Young D (1999) Improving the health behaviours of elderly people: randomised controlled trial of a general practice education programme. $B M J$ 319, 683-687.

Krach P, DeVaney S, DeTurk C \& Zink MH (1996) Functional status of the oldest-old in a home setting. Journal of Advanced Nursing 24, 456-464.

Mannel RC \& Dupuis S (1996) Life satisfaction. In Encyclopedia of Gerontology Age, Aging, and the Aged (Birren JE ed.). Academic Press, San Diego, pp. 59-64.

McAuley E, Blissmer B, Marquez DX, Jerome GJ \& Kramer AF (2000) Social relations, physical activity, and well-being in older adults. Preventive Medicine 31, 608-617.

McCamish-Svensson C, Samuelsson G, Hagberg B, Svensson T \& Dehlin O (1999) Social relationships and health as predictors of life satisfaction in advanced old age: results from a Swedish longitudinal study. International Journal Aging and Human Development 48, 301-324.

McCusker J, Bellevance F, Cardin S \& Belzile E (1999) Validity of an activities of daily living questionnaire among older patients in the emergency department. Journal of Clinical Epidemiology 52, 1023-1030.

Molarius A \& Janson S (2002) Self-rated health, chronic diseases, and symptoms among middle-aged and elderly men and women. Journal of Clinical Epidemiology 55, 364-370.

Morgan K, Dallosso HM, Arie T, Byrne EJ, Jones R \& Waite J (1987) Mental health and psychological well-being among the old and the very old living at home. British Journal of Psychiatry 150, 801-807.

Neugarten BL, Havighurst RJ \& Tobin SS (1961) The measurement of life satisfaction. Journal of Gerontology 16, 134-143.

Norton MC, Breitner JC, Welsh KA \& Wyse BW (1994) Characteristics of nonresponders in a community survey of the elderly. Journal of the American Geriatrics Society 42, 1252-1256.

Nyström A \& Segesten KA (1990) Peace of mind as an important aspect of old people's health. Scandinavian Journal of Caring Sciences 4, 55-62.

Paulhus DL \& van Selst M (1990) The spheres of control scale: 10 years of research. Personality and Individual Differences 11, 1029-1036.

Persson G, Bostrom G, Allebeck P, Andersson L, Berg S, Johansson L \& Thille A (2001) Chapter 5. Elderly people's health-65 and after. Health in Sweden: the National Public Health Report 2001. Scandinavian Journal of Public Health Supplement 58, 117-131.

Petersen MA, Groenvold M, Bjorner JB, Aaronson N, Conroy T, Cull A, Fayers P, Hjermstad M, Sprangers M \& Sullivan M (2003) Use of differential item functioning to assess the equivalence of translations of a questionnaire. Quality of Life Research 12, 373-385.

Pickering G, Brunet F, Roussel M \& Pastor JM (2001) Evaluation of the offer of physical activity for the elderly in a region of France. Archives of Gerontology and Geriatrics 33, 1-6.

Polit DF (1996) Data Analysis \& Statistics for Nursing Research. Appleton \& Lange, New York.

Polit DF \& Hungler BP (1999) Nursing Research Principles and Methods. Lippincott, Philadelphia.

Puri BK (2002) SPSS in Practice: An Illustrated Guide. Arnold, New York.

Rosenberg M (1979) Conceiving the Self. Basic Books, New York. 
Rowe JW \& Kahn RL (1998) Successful Aging. Dell Publishing, New York, pp. 125-142.

Spiro A \& Bossé R (2000) Relations between health-related quality of life and well-being: the gerontologist's new clothes. International Journal Aging and Human Development 50, 297-318.

Streiner DL \& Norman GR (1995) Health Measurement Scales: A Practical Guide to Their Development and Use. Oxford University Press, Oxford.

Stuck AE, Egger M, Hammer A, Minder CE \& Beck JC (2002) Home visits to prevent nursing home admission and functional decline in elderly people: systematic review and meta-regression analysis. The Journal of the American Medical Association 287, 1022-1028.

Swedish Institute (1999) The Care of the Elderly in Sweden. The Swedish Institute, Stockholm.

Tannenbaum C \& Mayo N (2003) Women's health priorities and perceptions of care: a survey to identify opportunities for improving preventative health care delivery for older women. Age Ageing 32, 626-635.

Thumboo J, Fong K-Y, Machin D, Chan S-P, Soh C-H, Leong K-H, Feng P-H \& Thio S-T (2003) Quality of life in an urban Asian population: the impact of ethnicity and socio-economic status. Social Science and Medicine 56, 1761-1772.

Vass M, Avlund K, Kvist K, Hendriksen C, Andersen CK \& Keiding N (2004) Structured home visits to older people. Are they only of benefit for women? A randomised controlled trial. Scandinavian Journal of Primary Health Care 22, 106-111.

Wagnhild G \& Young HM (1990) Resilience among older women. Journal of Nursing Scholarship 22, 252-255.

Walker A (2005) Quality of life in old age in Europe. In Growing Older in Europe (Walker A ed.). Open University Press, Suffolk, pp. 1-13.

Walker A \& Maltby T (1997) Ageing Europe. Open University Press, Guildford.

Watson D, Clark LA \& Tellegen A (1988) Development and validation of brief measures of positive and negative affect: the PANAS scales. Journal of Personality and Social Psychology 54, 10631070.

Wood V, Wylie M-L \& Sheafor B (1969) An analysis of a short selfreport measure of life satisfaction: correlation with rater judgements. Journal of Gerontology 24, 465-469. 